\title{
A comparative Study to assess the lifestyle of School Children with Underweight and Normal weight in Government Higher Secondary School
}

\author{
*Ms.Sandhiya*Prof.Sumathy P \&***Ms.SherinNithya
}

\section{Abstract:}

Introduction: Habits formed during childhood will have a long term impact on health and wellbeing. Good dietary pattern is essential for building of bones. Infants and children obviously need extra nutrition and proper physical activity and exercise for their growth and development. objectives: to assess the dietary habits of underweight children and normal weight children. To compare the dietary habits of underweight children and normal weight children. To compare the lifestyle of underweight children and normal weight children. Methodology: quantitative research approach with descriptive comparative research design was adopted to assess the lifestyle of school children. 60 children were selected by non-probability purposive sampling method in Government Higher Secondary School at Kirumampakkam, Puducherry. Results: Life style of both underweight and normal weight children were assessed under two areas, dietary habits and physical activity /exercise. It was noted that normal weight children were having good eating pattern and physical activity when compared to underweight children which was significant at $p<0.05$ level. Conclusion: Dietary habits of each individual and eating pattern are interlinked. This study results shows that majority of normal weight children followed a good dietary habits and physical activity compared to underweight children. And most of the underweight children had poor dietary habits and physical activity. It is highly essential that the under five children should be identified and proper awareness regarding dietary habits and physical habits should be imparted at the earliest.

Key Words: Assess, Underweight, Normal weight.

\section{INTRODUCTION}

Habits formed during childhood will have a long term impact on health and wellbeing. Good dietary pattern is essential for building of bones. Infants and children obviously need extra nutrition and proper physical activity and exercise for their growth and development[1]. The most important thing in life is a good health. 
It is widely recognized that a healthy childhood is the foundation for a healthy adult life. ${ }^{[2]} \mathrm{A}$ normal weight is referred to as child between 90 to $110 \%$ and above $110 \%$ referred as obesity (Gomez ' classification ). Normal Weight is also indicated

in terms of body Mass Index value between to 25 are considered as having normal weight between 25 to 29 are considered as having obesity and below 18 are considered as underweight. WHO ). Over half the world's underweight children live in India, Bangladesh and Pakistan , says a new UNICEF report on the global progress on children's issue. About 5.6 million children worldwide die every year for lack of adequate nutrients, approximately $47 \%$ of Indian's under- five population is underweight $[3]$.

India is home to 42 percent of the world's underweight children and 31 percent of its stunted children, according to 2010 Global Hunger Index report. The prevalence of underweight was highest, over $50 \%$ among children below 6 years old, in both Bangladesh, and India [4]. A study of Global Hunger states that India has highest prevalence of underweight children. Prevalence of Diabetes mellitus and Cardiovascular Diseases are increasing in Urban India. Proportion of overweight children increased from $4.94 \%$ in 2011 to 6. 57 in 2012. Life style and diet are the major factors that determine the weight of the child [5].

The most common cause of being underweight is primarily malnutrion caused by unavailability of adequate food effects of primary malnutrition may be amplified by disease, even easily treatable diseases such as Diarrhea may lead to death[6]. Some people are under weight due to genetics, others due to poverty. Being under weight can sometimes be the result of mental and physical disease such as Hypothyroidism,

Cancer, or Tuberculosis. People with eating disorders are likely to become underweight[7].

\section{OBJECTIVES}

- To assess the dietary habits of underweight children and normal weight children.

- To compare the dietary habits of underweight children and normal weight children.

- To compare the life style of underweight children and normal weight children.

\section{METHODOLOGY:}

Quantitative research approach with descriptive comparative research design was adopted to assess the lifestyle of school children. 60 children were selected, ,30normal weight children and 30 - under weight children by non-probability purposive sampling method in Government Higher Secondary School at Kirumampakkam , Puducherry.

Development of data collection instrument has two sections. Part -I Consists of demographic variables which comprises of several demographic details of the children ,Part II- consists of section A Dietary habits and section B - Physical activity and exercise. Scoring procedure is each correct habits of the child was scored 5 marks, poor habit of the child was scored as 1 mark.

\section{Results:}

The results revealed that the consumption of breakfast, pulses, fruits, milk, greens, inclusion of ghee /butter in the diet, and consumption of eggs, was statistically significant at $\mathrm{p}<0.05$ level, between children with normal weight and 
underweight, which implies that children who were underweight did not have the practice of having a regular dietary pattern.

With regard to engage in physical activity 13 (44\%) of the children belonging to under weight category did not take part in the physical activity daily, where as children with normal weight, 16(53\%) engaged in Physical Activity daily.

Table 1: Comparison of life style among school children with underweight and normal weight

$\mathrm{N}=60$

\begin{tabular}{|c|c|c|c|c|c|}
\hline \multirow{2}{*}{ S.N } & Variable & Categories & Mean & $\begin{array}{c}\text { Standard } \\
\text { deviation }\end{array}$ & \multirow{2}{*}{ P Value } \\
\cline { 1 - 3 } 1. & \multirow{2}{*}{ Life Style } & Underweight & 77.4 & 9.77 & \multirow{2}{*}{$.001^{*}$} \\
\cline { 1 - 3 } & & Normal Weight & 95.3 & 5.05 & \\
\hline
\end{tabular}

*Significant at $p<0.05$ level

Table 1: The table reveals that, the mean lifestyle of underweight children score was 77.4 and the normal weight children score was 95.3. It was higher than the mean of underweight children. The standard deviation of lifestyle of underweight children was 9.77 and normal weight children was 5.05. T he obtained ' $p$ ' value was 0.001 . Which implies that there was significant difference between the lifestyle practices of underweight and normal weight children at $\mathrm{p}<0.05$ level.

\section{CONCLUSION:}

Dietary habits of each individual and eating pattern are interlinked. This study results shows that majority of normal weight children followed a good dietary habits and physical activity compared to underweight children. And most of the underweight children had poor dietary habits and physical activity. It is highly essential that the under five children should be identified and proper awareness regarding dietary habits and physical habits should be imparted at the earliest.

\section{REFERENCES:}

1. Bisai $S$ et al. Prevalence of under nutrition among children aged 2-13 years, World nutrition Res. 2016:2275- 78. [Medscape].

2. Behrman ,Kliegman, Jenson, Nelson text book of Paediatrics. 17 th edition. Jaypee brothers medical publishers(2012)

3. Kasmai .S et al. Trend in the Prevalence of physical activity. National Youth risk behavior survey Res. 2016:1132- 49. [Pupmed]

4. Ogden CL, Carroll MD ,Flegal KM . High body mass index for age among Indian children and adolescents 2012: 789- 805.

5. Surajgupte A short textbook of pediatrics $10^{\text {th }}$ edition Pg No: 50- 55.[2011]

6. Ramachandra P. nutrition and child survival in India 2012(cited on January) webmed.

7. Verma LK Mani .S Body image and eating behavior in interethenic Adolescent Growth Res. 2010 :1672-83 